\title{
Validity of Resistive Index in Intracranial Pressure Monitoring among Questionable Hydrocephalic Infants
}

\author{
MOHAMED M. EL-MAGHRABI, M.D.*; AHMED A. ARAB, M.D.*; MOATAZ A. EL-AWADY, M.D.* and \\ AHMED TURKEY, M.D.**
}

The Departments of Neurosurgery* and Radiology**, Faculty of Medicine, Benha University

\begin{abstract}
Background: Resistive Index (RI) measurement by Transcranial Doppler sonography was used as a bedside safe, noninvasive technique that helpful for the assessment of vascular hemodynamics in various conditions; such as defect in brain perfusion associated with hydrocephalus.

Objective: To evaluate validity of resistive index as reflecting Intracranial Pressure (ICP).

Patients and Methods: This is a cross-sectional study which included thirty infants with query hydrocephalus, and they underwent RI measurement of middle cerebral artery at Radiology Department of Benha University Hospital then ICP monitoring at the Neurosurgery Department of Benha University and Benha Children Hospitals through the period from April 2015 to January 2017.

Results: This study includes thirty infants with query hydrocephalus, twenty four boys and six girls, with mean age $5.83 \pm 3.43$ (ranged from 1 to 12 months). There is direct correlation between RI and ICP as RI increase with increasing ICP, which is statistically significant $(p<0.05)$. As regard RI, there is significant difference between infants with high ICP and others with normal ICP $(p=0.001)$. The best detected RI cut off point among infants is 0.7 as it has high sensitivity, specificity and accuracy.

Conclusion: RI is valid as a predictor of increased ICP so it can be used as a successful non invasive method instead of invasive technique for evaluating intracranial pressure in diagnosis of hydrocephalus among infants.
\end{abstract}

Key Words: Resistive index - Intracranial pressure monitoring.

\section{Introduction}

AMONG infants with hydrocephalus, it is not easy to establish a diagnosis aiming to initiate a treatment modality especially drainage procedures [1]. Assessment of intracranial pressure (ICP) is essential in the management of conditions with elevated ICP and various methods were used to assess ICP

Correspondence to: Dr. Mohamed M. El-Maghrabi, E-Mail: dr elmaghrabi@yahoo.com mohamed.almaghreby01@,fmed.bu.edu.eg whether invasive or non invasive. While some author were comfortable with invasive method as direct cannulation (the most accurate but with risks), and direct intraparenchymal devices (accurate with less risks) [2], others had suggested non invasive use of Transcranial Doppler (TCD) and its indices as Resistive Index (RI) which was used as a bedside safe, non invasive technique that was helpful for the assessment of vascular hemodynamics in various conditions; such as defect in brain perfusion associated with hydrocephalus [3] .

The aim of this study is to evaluate the use of TCD and RI in questionable hydrocephalic infants subjected for possible drainage procedure, and to assess its validity to reflect the increase of ICP. And to try to establish a cut off point of RI value that may correlate to initiate a decision for surgery.

\section{Patients and Methods}

This is a cross-sectional study which included thirty infants with query hydrocephalus, not proved by clinical nor ordinary radiological findings, and they underwent RI measurement of Middle Cerebral Artery (MCA) at Radiology Department of Benha University Hospital then ICP monitoring at the

\footnotetext{
List of Abbreviation:

RI : Resistive Index.

ICP : Intracranial Pressure.

MCA : Middle Cerebral Artery.

ICA : Internal Carotid Artery.

FET : Fischer Exact Test.

ROC : Receiver Operator Characteristic.

CT : Computerized Tomography.

MRI : Magnetic Resonance Imaging.

CSF : Cerebrospinal Fluid.

EDV : End Diastolic Velocity.

PI : Pulsatility Index.

TST : Trans-Systolic Time.
} 
Neurosurgery Department of Benha University and Benha Children Hospitals through the period from April 2015 to January 2017.

Patient population: Thirty infants, twenty four boys and six girls, with their age ranged from one month to twelve months (mean age $5.83 \pm 3.43$ ).

Radiological note: All patients underwent RI measurement by an equipment of a duplex Ultrasound colour flow mapper. The probes that used were sector, phased array cardiac and dedicated probe with a small imaging footprint and a Doppler frequency of 1.8 or $2 \mathrm{MHz}$. The examination done with the patient was in the supine position. Three acoustic windows were used: The trans-fontanel, temporal and the sub-occipital windows. For the temporal window, the examiner sit bedside on the patient's right, forearm resting on the patient's shoulder or chest to assure good stability and a little restraint of the child. The probe was placed just anterior to the tragus of the ear and superior to the zygoma and an axial grey-scale view of the base of the brain is obtained depicting the hypoechoic "gazelle track" or heart-shape cerebral peduncles and the echogenic star-shaped suprasellar cistern; these were the reference landmarks. In the colour mode, the circle of Willis projected anteriorly the MCA which was coded in red with flow towards the transducer. Switch to the spectral Doppler mode, a 5-mm wide Doppler sample gate was placed on the Internal Carotid Artery (ICA) bifurcation and moved towards the periphery along the MCA. Two to three velocity recordings were made from ICA bifurcation towards the periphery, and the highest velocity was recorded [4].

Operative note: Guided by Wiegand and Richards [2], supine baby under general anesthesia was put with head in flat neutral position. Under complete aseptic condition, insertion of 18 gauge intravenous cannula in lateral ventricle through lateral angle of anterior fontanel (27 Rt and $2 \mathrm{Lt}$ angles) or Rt lateral Kocher burr hole after skin incision in one baby of small anterior fontanel. Infusion set was connected to the cannula with measurement of the length of column of CSF (in $\mathrm{cm} \mathrm{H} 2 \mathrm{O}$ ) from heart level (mid head point), fixed column for five minutes and no straining by deep anesthesia, then removal of a system and dressing was applied.

Stevens, [5] suggested that the measurement of ICP $>27 \mathrm{~cm} \mathrm{H} 2 \mathrm{O}$ for $\geq 5$ minutes as a threshold for treatment of hydrocephalus, so we classified our study into normal ICP $\left(\leq 27 \mathrm{~cm} \mathrm{H}_{2} \mathrm{O}\right)$ and high ICP (>27 $\mathrm{cm} \mathrm{H}_{2} \mathrm{O}$ ).

\section{Statistical analysis:}

The program used was SPSS Version 20. Quantitative data were analyzed using mean and standard deviation, while frequency and percentage were used with qualitative data. Student $t$-test was used to compare means of two groups; correlation coefficient was used for correlation between RI and ICP. Fischer Exact Test (FET) was used to compare frequencies. Receiver Operator Characteristic (ROC curve) was used to measure validity of RI. A $p$ value $<0.05$ was considered statistically significant (*) while $>0.05$ statistically insignificant.

\section{Results}

This study includes thirty infants with query hydrocephalus underwent RI measurement of MCA then ICP monitoring, twenty four boys and six girls, with mean age 5.83 \pm 3.43 (ranged from 1 to 12 months). Table (1) shows that mean of RI is $0.70 \pm 0.11$ (range 0.35-0.88). ICP is divided into high and normal pressure, $66.7 \%$ and $33.3 \%$ respectively, (mean pressure is $27.2 \pm 8.29 \mathrm{~cm} \mathrm{H} 2 \mathrm{O}$ and ranges from 10 to 43 ).

There is direct correlation between RI and ICP, Fig. (1), as RI increase with increasing ICP, which is statistically significant $(p<0.05)$.

Table (2) shows that there is no significant difference between male and female infants as regard RI ( $p=0.056)$ while there is significant difference between infants with high ICP and others with normal ICP $(p=0.001)$.

Fig. (2) and Table (3) show that 0.7 is detected to be the best cut off point so RI is valid as a predictor of increased ICP. ROC curve shows that RI has $90 \%$ sensitivity, $90 \%$ specificity and $90 \%$ accuracy.

So we can classify the included infants, according to that cut off point of, into high RI (17 infants, $56.7 \%$ ) and normal RI (13 infants, $43.3 \%$ ).

Table (1): Distribution of the studied group.

\begin{tabular}{|c|c|}
\hline Variable & Value (30) \\
\hline $\begin{array}{l}\text { Age/m: } \\
\quad \text { mean } \pm \mathrm{SD} \\
\text { Range }\end{array}$ & $\begin{array}{l}5.83 \pm 3.43 \\
1-12\end{array}$ \\
\hline $\begin{array}{l}\operatorname{Sex} n(\%): \\
\text { Boys } \\
\text { Girls }\end{array}$ & $\begin{array}{l}24(80.0) \\
6 \quad(20.0)\end{array}$ \\
\hline $\begin{array}{l}\text { Resistive Index (RI): } \\
\text { Mean } \pm \text { SD (range) }\end{array}$ & $0.70 \pm 0.11(0.35-0.88)$ \\
\hline $\begin{array}{l}\text { Intra Cranial Pressure }(I C P \\
\text { Mean } \pm \mathrm{SD}(\text { range }) \\
\text { High ICP }(>27 \mathrm{~cm} \mathrm{H} 2 \mathrm{O}) \\
\text { Normal ICP }(\leq 27 \mathrm{~cm} \mathrm{H} 2 \mathrm{O})\end{array}$ & $\begin{array}{l}27.2 \pm 8.29(10-43) \\
20(66.7) \\
10(33.3)\end{array}$ \\
\hline
\end{tabular}


Table (2): Resistive index difference regarding sex and intracranial pressure.

\begin{tabular}{|c|c|c|c|c|c|}
\hline \multicolumn{2}{|l|}{ Variable } & \multicolumn{2}{|c|}{$\begin{array}{c}\text { Resistive Index } \\
\text { (RI) } \\
\text { mean } \pm \text { SD }\end{array}$} & $\begin{array}{c}\mathrm{St} \\
t \text {-test }\end{array}$ & $\begin{array}{c}p- \\
\text { value }\end{array}$ \\
\hline \multicolumn{6}{|l|}{ Sex: } \\
\hline \multicolumn{2}{|l|}{ Male } & \multicolumn{2}{|c|}{$0.72 \pm 0.09$} & \multirow{2}{*}{1.99} & \multirow[t]{2}{*}{0.056} \\
\hline Female & & $0.62 \pm 0.1$ & & & \\
\hline \multicolumn{6}{|c|}{ Intra Cranial Pressure (ICP): } \\
\hline High ICP & & $0.75 \pm 0.0$ & \multirow{2}{*}{\multicolumn{2}{|c|}{5.28}} & \multirow[t]{2}{*}{$0.001 *$} \\
\hline Normal ICF & & $0.59 \pm 0.1$ & & & \\
\hline \multicolumn{6}{|c|}{ *: Significant at $p=0.05$. } \\
\hline \multicolumn{6}{|c|}{ Table (3): Validity of RI as a predictor of high ICP. } \\
\hline Variable & $\begin{array}{l}\text { High ICP } \\
(20)\end{array}$ & $\begin{array}{c}\text { Normal ICP } \\
(10)\end{array}$ & $\mathrm{FE}$ & $\mathrm{ZT}$ & $\begin{array}{c}p- \\
\text { value }\end{array}$ \\
\hline$>0.70$ & $18(90.0)$ & $1(10.0)$ & 15. & 09 & $0.001 * *$ \\
\hline$\leq 0.70$ & $2(10.0)$ & $9(90.0)$ & & & \\
\hline AUC & 0.943 & & & & \\
\hline Stand Error & 0.041 & & & & \\
\hline $95 \% \mathrm{CI}$ & $0.86-1.0$ & & & & \\
\hline$p$-value & $0.001 * *$ & & & & \\
\hline Cut off point & 0.70 & & & & \\
\hline Sensitivity & 90.0 & & & & \\
\hline Specificity & 90.0 & & & & \\
\hline PPV & 94.7 & & & & \\
\hline NPV & 81.8 & & & & \\
\hline Accuracy & 90.0 & & & & \\
\hline
\end{tabular}

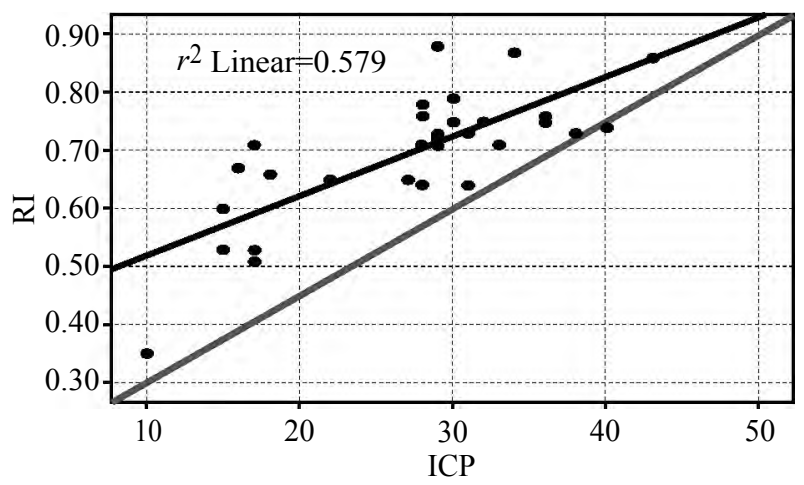

Fig. (1): Correlation between RI and ICP.

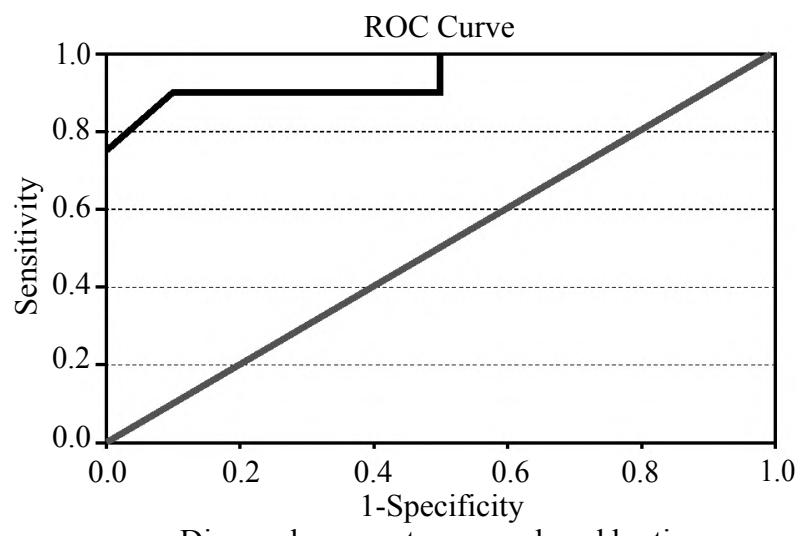

Diagonal segments are produced by ties

Fig. (2): ROC curve show validity of RI as a predictor of high ICP.

\section{Discussion}

Our query hydrocephalic infants who had symptoms, and signs suggesting this condition were subjected to evaluation with Computed Tomography (CT) and Magnetic Resonance Imaging (MRI), measuring of ICP invasively and non invasively, including the use of ultrasonography and TCD in order to obtain a reliable reason for surgery.

It is difficult to initiate a treatment modality especially drainage procedures on only progressive vetriculomegally on consecutive imaging studies, or the presence of clinical criteria of elevated ICP. The risk of initiating treatment depending on CT and MRI may out weight benefits as ICP values where normal or minimally elevated [1]. Infantile hydrocephalus is characterized by increased accumulation of Cerebrospinal Fluid (CSF) in cerebral ventricles with its enlargement, it occurred due to disturbance in production, flow, or absorption of CSF, and led to a series of pathophysiological changes with raised intracranial pressure ICP, decreased intracranial compliance, and alteration in cerebral circulation [6].

In hydrocephalic patients, the mean ICP was $20.5 \pm 8.5 \mathrm{~cm} \mathrm{H} 2 \mathrm{O}$ and the range form $10-25 \mathrm{~cm} \mathrm{H} 2 \mathrm{O}$ by several authors [7], others claimed normal value for children using lumbar puncture is $12-28 \mathrm{~cm}$ $\mathrm{H} 2 \mathrm{O},[8,9]$ and they suggested measurement $>27 \mathrm{~cm}$ $\mathrm{H} 2 \mathrm{O}$ for $\geq 5$ minutes with symptoms and signs of hydrocephalus as the threshold for treatment [5] Most of the studies depended on measurement with lumbar puncture, that was considered unreliable and significantly overestimates the ICP in children [10] .

In our study we used direct ICP measurement invasively by cannulation of lateral ventricle in supine anaesthetized babies, we found ICP ranging from 10 to $43 \mathrm{~cm} \mathrm{H} 2 \mathrm{O}$ with mean ICP $27.2 \pm 8.29 \mathrm{~cm}$ $\mathrm{H} 2 \mathrm{O}$, anaesthesia may alter the real value of ICP but at least it avoid physiologic events as sneezing, coughing, stressing, and crying that changes the readings.

TCD is a bedside, non invasive test for monitoring cerebral circulation that could be repeated for follow-up. With increased ICP, cerebral vessels are stretched, displaced, compressed leading to increased vascular resistance. This is reflected on Doppler curve parameters with decreased End Diastolic Velocity (EDV) of blood flow, increased RI, and Pulsatility Index (PI), so it can be used in diagnosing and following infants with hydrocephalus. Normal values for RI in infants at MCA ranged from 0.55 to 0.74 with mean $0.63 \pm 0.08$, 
[11] resistive index could be influenced by extracranial and intracranial factors increasing and decreasing it, factors that increased RI such as acute intracranial hypertension, intraventricular hemorrhage, intracerebral hemorrhage, hypocapnia, blood hyperviscosity, decreased cardiac output, congenital heart disease with left to right shunt, and also RI increased in brain congestion, cerebral arteriovenous malformation, seizures, hypercapnia, hypoxia, increased cardiac output, and right sided heart failure [12].

Bada et al., was the first to describe the relation between increased RI and increased ICP in preterm infants with post hemorrhagic hydrocephalus, [13] then Hill and Volpe assessed it again in 11 patients with increased ICP, all of them, had increased RI, of them 9 out 11 had ventriculomegally [14]. Goh et al., found good intra-individual correlation of RI to increased ICP in newborn and infants, and less correlation in older children, [15] and then they studied increased RI in relation to increased ICP and ventriculomegally, they found that increased RI was caused by increased ICP and not by ventriculomegally alone [16]. Qualitative indices as RI and PI that had disadvantage and are affected by heart rate and had a broad range reference value especially in children, therefore, they concluded insufficiency of RI and PI in assessing ICP and they induces new index Trans-Systolic Time (TST) for ICP assessment [17]. Leliefield et al., [18] analyzed the TST in relation to ICP in infants with hydrocephalus, and found it to be significant $(p<0.005)$ but also in their study relations of RI and PI to ICP were significant $(p<0.05)$, and concluded closer relation of TST than RI and PI to increased ICP.

In our study, there is a direct correlation between $\mathrm{RI}$ and ICP, and as regard RI, there is a significant difference between infants with high ICP and others with normal ICP.

Anterior cerebral artery Doppler parameter was assessed and was found significant increased in basal and compressive RI in patients with need for drainage procedure, and there was significant decrease in RI after drainage. For basal RI sensitivity was $72.5 \%$, specificity $80 \%$, and diagnostic accuracy $75 \%$ [19].

In our study, basal RI sensitivity was $90 \%$, specificity $90 \%$ and diagnostic accuracy $90 \%$ claiming the validity of RI as a predictor of ICP with the best detected cut off point of RI is 0.7. In general, TCD in infants with suspected hydrocephalus can be used as a routine non invasive method for assessing and monitoring cerebral circulation and indirectly monitoring ICP adding to other investigation more reliability for taking the decision of surgery according this non invasive technique.

\section{Conclusion:}

$\mathrm{RI}$ is valid as a predictor of increased ICP so it can be used as a successful non invasive method instead of invasive technique for evaluating intracranial pressure in diagnosis of hydrocephalus with the best cut off point is 0.7 among infants.

\section{Acknowledgment:}

The authors thank parents of all included infants.

\section{Funding:}

This study had no funding from any resource.

\section{Competing interests:}

The authors declare that they have no conflict of interest.

\section{Ethical approval:}

This research accepted by Research Ethics Committee (REC) of faculty of medicine, Benha University (chairman: Prof/Ibrahim El-Gendy).

All procedures performed in studies involving human participants were in accordance with the ethical standards of the institutional and/or national research committee and with the 1964 Helsinki declaration and its later amendments or comparable ethical standards. A written informed consent was obtained from each parent of participants after explaining all steps of this study.

\section{Authors' contributions:}

Mohamed El-Maghrabi, Ahmed Arab and Moataz El-Awady performed the clinical part of ICP monitoring of the study, analyzed the data and wrote with meticulous revision of the paper.

Ahmed Turkey performed the radiological measurements of the study and wrote radiological side of the paper.

\section{References}

1- REKATE H.L.: Treatment of hydrocephalus. In Cheek W.R., Marlin A.E., McLone D.G., et al (Eds): Pediatric Neurosurgery, ${ }^{3 r d}$ ed. Philadelphia: WB Saunders, p. 202, 1994.

2- WIEGAND C. and RICHARDS P.: Measurement of in tracranial pressure in children: A critical review of current methods. Developmental Medicine \& Child Neurology, 49: 935-41, 2007.

3- AHMAD I., WAHAB S., CHANA R.S., KHAN R.A. and WAHAB A.: Role of transcranial Doppler and pressure provocation in evaluation of cerebral compliance in 
children with hydrocephalus. H.K. J. Paediatr. (new series), 13: 110-5, 2008.

4- VERLHAC S.: Transcranial Doppler in children. Pediatric Radiology, 41 (1): S153-65, 2011.

5- STEVENS R.D., SHOYKHET M. and CADENA R.: Emergency Neurological Life Support: Intracranial Hypertension and Herniation. Neurocrit Care, 23 (2): S7682, 2015.

6- De RIGGO J., KOLAROVSZKI B., RICHTEROVA R., KOLAROVSZKA H., SUTOVSKY J. and DURDIK P.: Measurement of the blood flow velocity in the pericallosal artery of children with hydrocephalus by transcranial Doppler ultrasonography-preliminary results. Biomed. Pap. Med. Fac. Univ., 151 (2): 285-9, 2007.

7- WELCH K.: The intracranial pressure in infants. J. Neurosurg, 52: 693-9, 1980.

8- AVERY R.A., SHAH S.S., LICHT D.J., SEIDEN J.A., HUH J.W., BOSWINKEL J., RUPPE M.D., CHEW A., MISTRY R.D. and LIU G.T.: Reference range for cerebrospinal fluid opening pressure in children. N. Engl. J. Med., 363 (9): 891, 2010.

9- AVERY R.A.: Interpretation of lumbar puncture opening pressure measurements in children. J. Neuroophthalmol., 34 (3): 284-7, 2014.

10- CARTWRIGHT C. and IGBASEIMOKUMO U.: Lumbar puncture opening pressure is not a reliable measure of intracranial pressure in children. J. Child. Neurol., 30 (2): 170-3, 2015.

11-MINARIK M.: Transkraniálna farebná duplexná sonografia doj`ciat (1 st ed), Osveta, ISBN 80-8063-041-0, Martin, Slovak Republic; 2000.

12- KOLAROVSZKI B. and ZIBOLEN M.: Transcranial Doppler ultrasonography in the management of neonatal hydrocephalus. In Pant S., Cherian I. (eds): Hydrocephalus, $1^{\text {st }}$ ed. Croatia: Tech Rijeka, p. 13 1-52, 2012.

13- BADA H.S., MILLER J.E., MENKE J.A., MENTEN T.G., BASHIRU M.S.M., BINSTADT D., SUMNERA D.S. and KHANNA N.N.: Intracranial pressure and cerebral arterial pulsatile flow measurements in neonatal intraventricular haemorrhage. J. Pediatr., 100 (2): 291-6, 1982.

14- HILL A. and VOLPE J.J.: Decrease in pulsatile flow in anterior cerebral arteries in infantile hydrocephalus. Pediatrics, 69 (1): 4-7, 1982.

15-GOH D., MINNS R.A. and PYE S.D.: Transcranial Doppler (TCD) ultrasound as a noninvasive means of monitoring cerebrohaemodynamic change in hydrocephalus. Eur. J. Pediatr. Surg., 1 (1): S14-17, 1991.

16- GOH D. and MINNS R.A. : Intracranial pressure and cerebral arterial flow velocity indices in childhood hydrocephalus: Current review. Childs. Nerv. Syst., 11 (7): 3926, 1995 .

17- HANLO P.W., PETERS R.J., GOOSKENS R.H., HEETHAAR R.M., KEUNEN R.W., VAN HUFFELEN A.C., TULLEKEN C.A. and WILLEMSE J.: Monitoring intracranial dynamics by transcranial Doppler-a new Doppler index: Trans systolic time. Ultrasound Med. Biol., 21 (5): 613-21, 1995.

18- LELIEFELD P.H., GOOSKENS R.H., PETERS R.J., TULLEKEN C.A., KAPPELLE L.J., HAN K.S., REGLI L. and HANLO P.W.: New transcranial Doppler index in infants with hydrocephalus: Transsystolic time in clinical practice. Ultrasound. Med. Biol., 35 (10): 1601-6, 2009.

19- GERA P., GUPTA R., SAILUKAR M., AGARWAL P., PARELKAR S. and OAK S.: Role of transcranial Doppler sonography and pressure provacation test to evaluate the need for cerebrospinal fluid drainage in hydrocephalic children. Annual Conference of IAPS, Ahmadabad, 2002.

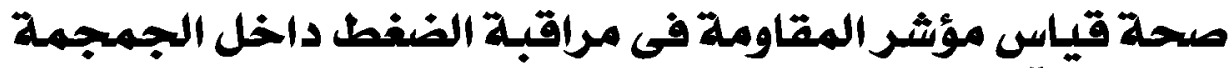

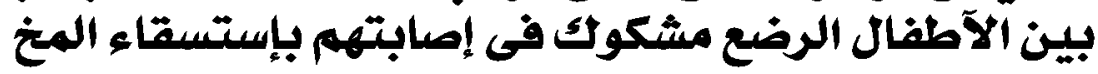

\author{
الخلفية: تم إستخدام قياس مؤشر المقاومة من قبل بإستخدام دويلر الموجات فوق الصوتية عبر الجمجمة كتقنية سريرية آمنة، ومفيدة

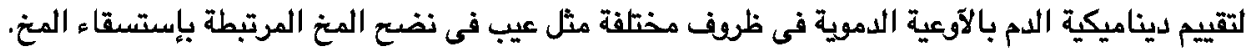$$
\text { الهدف: تهدف الدراسة لتقييم صحة مؤشبر المقاومة كعاكس للضفط داخل الجمجمة. }
$$ \\ المرضى والطريقة: هذه دراسة مستعرضة شملت ثلاثين طفلا رضيعا يعانوف من إثتباه في إستسقاء المتخ، وقد خضعوا لقياس مؤشر

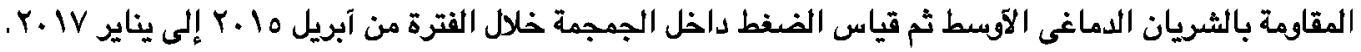

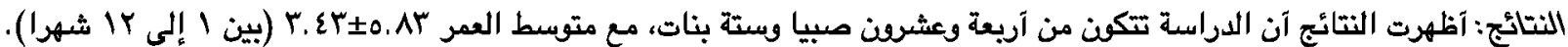

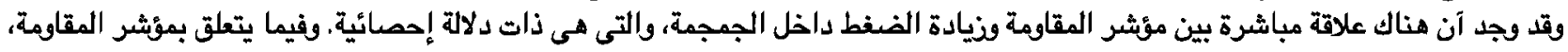

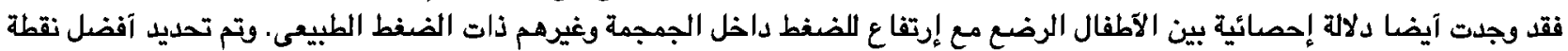

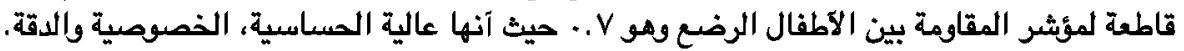 \\ الإستتاج: مؤشر المقاومة هو مؤثر فعال لزيادة الضفط داخل الجمجمة بحيث يمكن إستخدامه كطريقة ناجحة وآمنة بدلا من التقنية الغازية

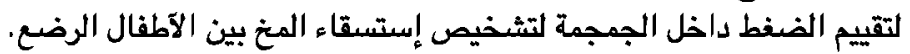

